KEBERADAAN KONSEP RULE BY LAW (NEGARA BERDASARKAN HUKUM) DIDALAM TEORI NEGARA HUKUM THE RULE OF LAW

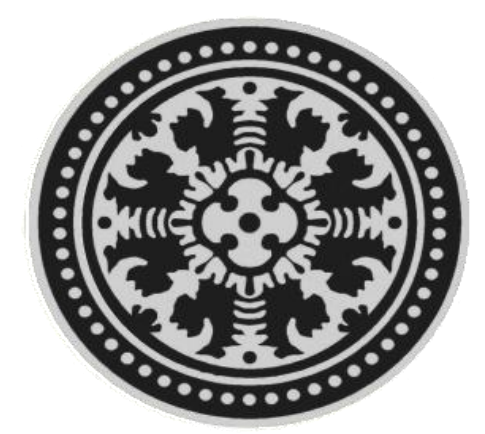

MADE HENDRA WIJAYA

0990561025

HUKUM PEMERINTAHAN

PROGRAM PASCASARJANA

MAGISTER ILMU HUKUM

UNIVERSITAS UDAYANA

DENPASAR

2013 


\section{KEBERADAAN KONSEP RULE BY LAW (NEGARA BERDASARKAN HUKUM) DIDALAM TEORI NEGARA HUKUM THE RULE OF LAW \\ Oleh MADE HENDRA WIJAYA}

This research titled, the existence of the concept of rule by law (state law) within the state theories of law the rule of law, which is where the first problem: How can the advantages of Rule by Law in the theory of law Rule of Law?, How is the dis advantages of a concept of Rule by law in the theory of law Rule of Law.

This research method using the method of normative, legal research that examines the written laws of the various aspects, ie aspects of the theory, history, philosophy, comparative, structure and composition, scope, and content, consistent, overview, and chapter by chapter, formality, and the binding force of a law, and the legal language used, but did not examine or imlementasi applied aspects. By using this approach of Historical analysis and approach of legal conceptual analysis.

In this research have found that the advantages of the concept of Rule by Law lies in the providing of certainty, can also be social control for the community, thus ensuring all citizens in good order at all reciprocal relationships within the community. And Disadvantages of the concept of Rule by Law if the Law which legalized state action is not supported by democracy and human rights, and the principles of justice, there will be a denial of human rights, widespread poverty, and racial segregation, and if the law is only utilized out by the authorities as a means to legalize all forms of actions that violate human can inflict totalitarian nature of the ruling.

Keywords : Rule by Law, State Law, the Rule of Law 


\section{PENDAHULUAN}

Dalam pengertian Negara Hukum Klasik terdapat dua tipe pokok negara hukum, yaitu

a. Type Eropa Kontinental, yang berdasarkan pada kedaulatan hukum (rechtsouvereiniteit), yang berintikan Rechtstaat (negara hukum)

b. Type Anglo Saxon, yang berintikan The Rule of Law;

Rechtstaat adalah sebuah konsep dalam pemikiran hukum Eropa Kontinental yang awalnya dipinjam dari hukum Jerman, yang dapat diterjemahkan sebagai "legal state", "state of law", "state of justice", or "state of rights" dimana pelaksanaan kekuasaan pemerintahan yang dibatasi oleh hukum ${ }^{1}$.

Frederich Stahl mengungkapkan setidaknya terdapat 4 unsur dari Rechstaat, yaitu ${ }^{2}$ :

1. Jaminan terhadap Hak Asasi Manusia;

2. Adanya pembagian kekuasaan;

3. Pemerintah berdasarkan Peraturan Perundang-undangan;

\footnotetext{
${ }^{1}$ Hayek, Friedrich , 1960, The Constitution of Liberty, University of Chicago Press, Chicago, USA, h. 199

2 Sulistiyono, Adi, 2007, Negara Hukum: Kekuasaan, Konsep, dan Paradigma Moral, Cetakan I, Lembaga Pengembengan Pendidikan (LPP) dan UPT Penerbitan dan percetakan UNS (UNS PRESS) Universitas Sebelas Maret, Surakarta, h. 32
}

4. Adanya Peradilan Administrasi Negara yang berdiri sendiri (independent).

Istilah The Rule of Law ditemukan dalam buku AV. Dicey yang berjudul Introduction To The Study of The Constitution (1952) ${ }^{3}$. Di dalam buku yang banyak dipakai dalam kajian tentang negara hukum ini, Dicey menjelaskan keunikan cara berhukum orang-orang Inggris yang menganut sistem common law. Dicey menarik garis merah dari cara berhukum tersebut sebagai sebuah konsep The Rule of Law dimana masyarakat dan pemerintah taat dan patuh kepada hukum sehingga ketertiban dapat dinikmati bersama-sama yang tidak ditemukan di beberapa negara Eropa lainnya.

A.V. Dicey menguraikan adanya 3 unsur penting dalam setiap negara hukum yang disebutnya dengan istilah "The Rule of Law", yaitu":

1. Supremacy of Law yaitu dominasi dari aturan-atauran hukum untuk menentang dan meniadakan

3 Dicey, A.V., 1952, INTRODUCTION TO THE STUDY OF THE LAW OF THE CONSTITUTION, Mc Millan and Co, Limited St. Martin's Street, London,Part II. Chapters IV-XII, http://www.constitution.org/cmt/avd/law_con.htm, artikel diakses18-01-2011, pukul 12,30

4 Hadjon, Philiphus M, 2007,Perlindungan Hukum Bagi Rakyat di Indonesia, sebuah studi tentang Prinsip-Prinsipnya, Penanganannya oleh Pengadilan dalam Lingkungan Peradilan Umum dan Pembentukan Peradilan Administrasi, Perabadan, h. 75 
kesewenang-wenangan, dan kewenangan bebas yang begitu luas dari pemerintah;

2. Equality Before the Law yaitu persamaan di hadapan hukum atau penundukan yang sama dari semua golongan kepada ordinary law of the land yang dilaksanakan oleh ordinary court ini berarti tidak ada orang yang berada diatas hukum, baik pejabat maupun warga negara biasa, berkewajiban untuk mentaati hukum yang sama;

3. Due Prosess of Law atau terjaminnya hak-hak manusia oleh konstitusi yang merupakan hasil dari "the ordinary law of land", bahwa hukum konstitusi bukanlah sumber, akan tetapi merupakan konsekwensi dari hak-hak individu yang dirumuskan dan ditegaskan oleh peradilan, singkatnya prinsipprinsip hukum privat melalui tindakan peradilan dan parlemen sedemikian diperluas sehingga membatasi posisi crown dan pejabat.

Dalam perkembangan mengenai negara hukum, adanya upaya untuk menghilangkan batasan pengertian negara hukum antara Rechtstaat dan The Rule of Law, seperti halnya berangkat dari embrio pemikiran para penggagas negara hukum, seperti John Lock dan Montesquieu. Brian Tamanaha mencoba melakukan terobosan dengan memformulasikan sebuah alternatif baru dalam konsep negara hukum, dimana Brian Tamanaha menawarkan pemisahan konsep The Rule of Law kedalam dua kategori dasar, formal dan substantif, yang kedua-duanya masing-masing memiliki tiga cabang atau format yang berbedabeda $^{5}$.

Didalam konsep negara hukum the Rule of Law terdapat konsep Rule by Law atau biasa disebut konsep tindakan negara harus berdasarkan hukum yang memiliki arti bahwa hukum menjadi suatu acuan bagi praktek atau tindakan yang dilakukan oleh negara atau pemerintah, dimana menurut Brian Z Tamanaha Rule by Law terdapat pada versi formal dari the Rule of Law ${ }^{6}$, dan konsep Rule by Law sangat popular digunakan oleh negara-negara modern. Didalam konsep Rule by Law merupakan sebuah gagasan bahwa hukum adalah sarana negara melakukan urusan, segala tindakan yang dilakukan oleh pemerintah, harus sesuai dengan aturan hukum. Sehingga apapun yang dikatakan oleh hukum adalah suatu perintah yang harus dilaksanakan oleh pemerintah, dan pemerintah lebih memilih konsep Rule by

\footnotetext{
${ }^{5}$ Tamanahan, Brian Z, 2004, On The Rule Of Law, History, Politics, Theory, Cambridge University Press, United.Kingdom, h.91

${ }^{6}$ Ibid, h 92
} 
Law sebagai cara karena dianggap paling nyaman untuk memerintah.

Rule by Law merupakan antithesis sebagai pelaksanaan kekuasaan kesewenang-wenangan oleh negara atau pemerintah. Rule by Law bagian dari bentuk konsep formal di dalam sistem teori negara hukum Rule of Law ${ }^{7}$.

Konsep Rule by Law sangat penting keberadaannya dalam negara hukum, maka dari hal tersebut penulis ingin mengetahui keberadaan konsep Rule by Law (tindakan negara berdasarkan hukum) didalam teori negara hukum Rule of Law. Dalam hal ini penulis tertarik untuk merumuskan permasalahan sebagai berikut:

1. Bagaimanakah kelebihan dari Rule by Law dalam teori negara hukum the Rule of Law?

2. Bagaimanakan kekurangan dari konsep Rule by Law dalam teori negara hukum the Rule of Law

Tujuan umum dari penelitian ini adalah untuk mengetahui tentang kelebihan dan kekurangan dari penerapan konsep Rule by Law dalam teori negara hukum the Rule of Law, sehingga hal ini dapat menjadi suatu tambahan pengetahuan dalam suatu sistem teori negara hukum the Rule of Law.

\section{METODE PENELITIAN}

\footnotetext{
${ }^{7}$ Ibid h.92
}

Metode penelitian ini menggunakan metode normatif, yaitu penelitian hukum yang mengkaji hukum tertulis dari berbagai aspek, yaitu aspek teori, sejarah, filosofis, perbandingan, struktur dan komposisi, lingkup, dan materi, konsisten, penjelasan umum, dan pasal demi pasal, formalitas, dan kekuatan mengikat suatu Undang-undang, serta bahasa hukum yang digunakan, tetapi tidak mengkaji aspek terapan atau imlementasi, sehingga penelitian hukum normatif sering disebut "penelitian hukum dokmatik" atau" penelitian hukum teoritis" (dogmatic or theoretical law reseach) ${ }^{8}$. Pendekatan analitis Sejarah (approach of Historical analysis), dan pendekatan analitis konsep hukum (approach of legal conceptual analysis.

\section{HASIL DAN PEMBAHASAN}

\section{Kelebihan Dari Rule By Law Dalam} Teori Negara Hukum The Rule of Law

Dalam membahas Rule by Law tentu tak tepas dari hubungan hukum dan kekuasaan, dimana Prof I Dewa Gede Atmaja di dalam bukunya Filsafat Hukum Dimensi Tematis \& Historis, yang mengutip pendapatnya Blaise Pascal mengatakan bahwa "hukum tanpa

\footnotetext{
${ }^{8}$ Muhammad, Abdulkadir, 2004, Hukum dan Penelitian Hukum, PT. Citra Aditya Bakti, Bandung, h. 101-102
} 
kekuasaan adalah angan-angan, kekuasaan tanpa hukum adalah kelaliman"9.

N. M. Korkunov juga mengatakan bahwa "Whatever may be the state's organization, whatever powers it may have, the human conscience tends always to subject this power to legal rules. To the interests of power are necessarily opposed the principles of law. In submitting to the authority of the state the citizen requires of the organs of power a similar submission to law, because to whatever height the interest of authority of order may rise, it can never wholly annihilate and engulf men's other interests. In centralizing force into its hands the state thereby assures to all its citizens good order in all their mutual relations ${ }^{10}$. ( apapun mungkin dapat menjadi suatu organisasi negara, apapun kekuatan yang dimiliki, hati manusia cenderung untuk selalu tunduk kepada kekuasaan yang legal ( aturan-aturan hukum). Untuk kepentingan kekuasaan selalu menentang prinsip-psrinsip hukum. Tunduk kepada otoritas negara, warga negara mengharuskan organ-organ kekuasaan melakukan pengajuan yang mirip atau serupa dengan hukum, karena

\footnotetext{
${ }^{9}$ Atmaja, I Dewa Gede, 2013, Filsafat Hukum ,Dimensi Tematis \& Historis, Setara Press, Malang, h.63

${ }^{10}$ Korkunov, N. M. 1922, General Theory of Law, Second Edition, English Translate By W. G. hastings. The Macmillan Company, New York, h. 371
}

sekuat apapun kepentingan perintah kekuasaan meningkat, tidak pernah dapat sepenuhnya memusnahkan dan menelan kepentingan manusia lainnya. Berlakunya pemusatan (sentralisasi) ke tangan negara sehingga menjamin semua warga negarannya dalam tatanan yang baik di semua hubungan timbal balik dalam masyarakat.

Negara dalam hal memegang kekuasaan memiliki arti bahwa fungsi untuk membuat suatu masyarakat yang teratur, serta menegakkan hukum menjadi bermanfaat dan efektif, serta dibalik itu hukum juga dapat menjadi alat untuk membatasi tidakan sewenang-wenang oleh negara.

Rule By law di dalam teori negara hukum the Rule of Law yang merupakan intuisi dasar" yang mendasari dari the Rule of Law adalah hukum harus mampu membimbing prilaku subyeknya ${ }^{11}$. Lain kata bahwa the Rule of Law juga menekankan karakteristik dan manfaat dari aturan, dimana Undang-Undang dianggap sebagai jenis aturan dan tujuan aturan yang dianggap membimbing prilaku manusia. Yaitu prilaku dari penguasa dan rakyatnya, dimana konsep Rule by Law digunakan sebagai pembatas dari tindakan bebas dari penguasa yang tujuannya adalah agar

\footnotetext{
${ }^{11}$ Raz, Joseph, 1979, "The Rule of Law and Its Virtue, " in The Authority of Law, Clarendon Press , Oxford:, h 214
} 
penguasa tidak melaksanakan kekuasaannya secara sewenang-wenangan serta pembatas dari prilaku dan tindakan masyarakatnya agar terciptanya suatu ketertiban dan keamanan.

Konsep Rule by Law memberikan penekanan kepada adanya kepastian hukum. Dimana hukum dapat menjadi sebuah alat yang memiliki kepastian untuk memberikan ruang lingkup dan batasan yang sudah jelas bagi para subyek hukum, sehingga subyek hukum akan bertindak sesuai dengan apa yang sudah ditentukan, penentuan terhadap tindakan subyek hukum tersebut dirumuskan dalam bentuk Undang-Undang.

Asas kepastian hukum merupakan sebuah asas dalam negara hukum yang mengutamakan landasan Peraturan Perundang-undangan, Kepatuhan, dan keadilan dalam setiap kebijakan penyelenggaraan negara. Menurut Arief Sidharta bahwa negara hukum menjamin kepastian hukum terwujud dalam masyarakat dan prediktibilitasnya sangat tinggi. Sehingga dinamika kehidupan bersama dalam masyarakat bersifat "predictable" atau dapat diramalkan ${ }^{12}$.

${ }^{12}$ Sidharta, Arief , 2004, "Kajian Kefilsafatan tentang Negara Hukum", dalam Jentera (Jurnal Hukum), "Rule of Law", Pusat Studi Hukum dan Kebijakan (PSHK), edisi 3 Tahun II, November, Jakarta h.124-125
Didalam konsep Rule by Law yang berisiskan asas kepastian hukum, tentunya memberikan legalitas yang tinggi dalam menjalankan aturan hukum, dimana legalitas merupakan sebuah nilai inti, hak asasi manusia, dalam arti Nullum crimen, nulla poena sine lege $e^{13}$ (Tidak ada kejahatan, tak ada hukuman tanpa hukum) yang sebenarnya berarti tidak hanya memberikan jaminan kebebasan manusia, tapi juga melindungi individu dari tindakan kesewenang-wenangan atau penyalahgunaan kekuasan dan tindakan yang tidak adil oleh penguasa kepada individu dan warga masyarakat, sehingga terciptanya penjaminan keadilan dan transparasi dari kekuasaan kehakiman.

Konsep Rule by Law dapat memberikan suatu kontrol sosial dalam kehidupan bermasyarakat, dimana aktivitas yang dilakukan penguasa dapat di kontrol agar tidak melakukan tindakan kesewenang-wenangan dalam melaksanakan tugasnya, serta masyarakat dapat lebih mudah memantau kegiatan yang dilakukan oleh pemerintah apakah kegiatan yang dilakukan pemerintah tersebut sudah sesuai dengan Undangundang atau tidak. Di lain pihak

${ }^{13}$ Crisan, Julia,2010, The principles of legality "nullum crimen, nulla poena sine lege" and their role, Effectius Newsletter, Issue 5, France, h.1 
pemerintah dalam mengarahkan kehidupan masyarakat lebih tertib, sehingga kehidupan masyarakat sesuai apa yang dikatakan oleh Undang-Undang dan sesuai dengan apa yang diramalkan oleh pembuat Undang-Undang.

Sehingga mendapatkan kesesuaian antara aturan yang diberlakukan dengan penerapannya, yang berarti masyarakat secara individu dilindungi haknnya sesuai harapan mereka, dan pemerintah juga secara berdaulat melaksanakan tindakannta sesuai dengan aturan yang di tetapkan.

Konsep Rule by Law ini juga telah digunakan oleh Napoleon, dan dia percaya bahwa Undang-Undang Napoleon mengantisipasi semua kasus yang mungkin muncul di masa depan, dimana tafsiran terperinci dari Undang-Undang ${ }^{14}$. Kala itu politik dan sosial di Francis sangat stabil. Pengacara dan hakim di francis, serta keseluruhannya dengan sungguh-sungguh berusaha untuk menerapkan UndangUndang, dengan harapan mampu memecahkan semua masalah hukum di francis pada kal itu ${ }^{15}$.

Dalam konsep Rule By Law, tentu tak lepas dari Peraturan Perundang-undangan. Maka kelebihan dari konsep Rule by Law

\footnotetext{
${ }^{14}$ Frank, Jerome,1963, Law and Modern Mind, Achor Books Donbeday \&Company Inc, New york, USA, diterjemahkan oleh Astuti, Rahmani, 2013,Jerome Frank, Hukum \& Pemikiran Modern, Cet I, Nuansa Candekia, Bandung, h. 261

${ }^{15}$ Ibid
}

dapat dilihat juga melalui fungsi Peraturan Perundang-undangan dibagi menjadi dua kelompok utama, yaitu fungsi Internal dan fungsi eksternal ${ }^{16}$.

1. Fungsi internal ${ }^{17}$. Fungsi internal meliputi:
a. Fungsi penciptaan hukum (rechtschepping) ${ }^{18}$;

b. Fungsi pembaharuan hukum (Law reform $)^{19}$;
c. Fungsi integrasi Pluralisme sistem hukum $^{20}$;




\section{d. Fungsi kepastian hukum (rechtzekerheid, legal certainty) $^{21}$.}

2. Fungsi Eksternal ${ }^{22}$ :

a. Fungsi Perubahan ${ }^{23}$;

b. Fungsi stabilitasi ${ }^{24}$;

c. Fungsi kemudahan ${ }^{25}$.

Rule by Law secara idealnya diterapkan dapat dilihat berdasarkan Filosofis mengenai kekuasaan negara harus tunduk kepada hukum yang dikaji oleh tiga ahli hukum tentang negara yakni $^{26}$ :

1. Von Ihering berpendapat; bahwa hukum akan memiliki makna yang sesungguhnya jika penguasa yang memerintah rakyat yang

Pluralisme sistem hukum sepenuhnya tergantung dalam masyaraka

${ }^{21}$ Ibid 142, Kepastian hukum merupakan asas penting dalam tindakan hukum yang dilakukan negara dan penegakan hukum. Peraturan Perundang-undangan telah memberikan kepastian hukum yang lebih tinggi daripada hukum kebiasaan, hukum adat, atau hukum yang berasal dari jurisprudensi

${ }^{22}$ Ibid h.143, keterkaitan Peraturan Perundangundangan dengan lingkungan tempatnya berlaku, yang meliputi

${ }^{23}$ Ibid. h 143, Hukum adalah sebagai sarana pembaharuan ( Law as social engineering), yaitu peraturan perundang-undangan diciptakan untuk menciptakan perubahan dalam masyarakat di segala bidang aspek kehidupan masyarakat

${ }^{24}$ Ibid, Peraturan Perundang-undangan dapat berfungsi sebagai stabilitas, dimana kaidahkaidahnya bertujuan memberikan jaminan stabilitas masyarakat

${ }^{25}$ Ibid, Peraturan Perundang-undangan dapat dipergunakan sebagai sarana mengatur berbagai kemudahan. Dimana Peraturan Perundangundangan berisiskan ketentuan inisiatif dalam hal peringanan, penundaan, penyederhanaan

${ }^{26}$ Atmaja, I Dewa Gede, Op Cit, h. 64 diperintah keduanya tunduk pada hukum;

2. George Jellinek yang mengatakan memang negara sebagai pembentuk hukum, tetapi secara sukarela negara tunduk pada hukum yang diciptakannya;

3. Krabbe berpendapat, hukum eksis mendahului negara dan hukum mengikat begitu negara berdiri, karena hukum bersumber pada kesadaran hukum individu ${ }^{27}$.

Dalam kaitannya dengan kelebihan atau manfaat dari sistem Rule by Law ini terwujud, dalam pendapatnya prof I Dewa Gede Atmaja yang menyatakan "agar prinsip negara hukum terwujud dalam hubungan hukum dan kekuasaan, secara philosofis dipersyaratkan ${ }^{28}$ :

1. Kekuasaan yang memiliki nilai yang bermakna (meaningfulness), harus ditetapkan secara jelas ruang lingkupnya, arah dan batasbatasnya;

2. Penguasa atau pihak yang memegang kekuasaan memiliki kepabilitas, integritas, akuntabilitas, dan semangat mengabdi kepentingan umum (sense of public service); 
3. Rakyat sebagai pihak yang dikuasai, memiliki kesadaran hukum dalam arti disatukan pihak dapat menggunakan hak-hak sipil dan hak politik untuk melakukan control sosial, serta dilain pihak sadar akan kewajiban sebagai warga negara mematuhi aturan hukum (the duty of civil abdience $)^{29}$

\section{Kekurangan Dari Rule By Law Dalam Teori Negara Hukum The Rule Of Law}

Dalam berbagai banyak hal, jika terdapat kelebihannya maka tentu saja kekuranagnnya, dan tentu saja Konsep Rule by Law juga memiliki kekurangan. Brian Z Tanamahan mengatakan Rule by Law sebagai otoritas distorsi dari tradisi the Rule of Law, apabila tidak didukung oleh demokrasi dan hak asasi manusia, serta prinsip keadilan, maka akan terjadi pengingkaran terhadap hak asasi manusia, kemiskinan yang luas, dan segregasi rasial. Dimana hal tersebut dapat dilihat contoh apabila sistem hukum mendukung atau melegalkan tentang adanya perbudakan atau penghapusan ras tertentu. Maka itu menjadi kelemahan dalam konsep Rule by Law.

Joseph Raz menggunakan contoh di Amerika, dimana Raz mengatakan bahwa

\footnotetext{
${ }^{29}$ Ibid
}

di USA yang berpengang pada negara hukum the Rule of Law, bahwa ketika jaman perbudaan, sistem perbudakan ditegakkan secara hukum ${ }^{30}$.

Contoh pada saat totaliter Jerman, dimana semua perkataan Hitler adalah hukum yang berdaulat, bahkan keinginan hitler untuk memusnahkan ras yahudi dianggap legal. Totaliter yang dianut oleh hitler berasal dari pandangannya Hegel, dimana hegel berpendapat bahwa negara dan hukum bukan sesuatu yang kebetulan timbul di dunia ini dapat diterima. Kehidupan bersama manusia berkembang secara sepontan menjadi hidup bersama yang teratur. Keteraturan itu datang dari negara dan hukum. Bahwa negara timbul lepas dari segala persetujuan wargawargannya dan bahwa tidak terdapat suatu hukum di luar batas negara. Konsekuensi untuk hukum ialah satu-satunya hukum yang berlaku adalah hukum yang berasal dari negara, yaitu hukum positif ${ }^{31}$.

Menggunakan konsep Rule by Law secara murni tentu saja akan membuat kita berhukum dengan teks ${ }^{32}$. Yaitu dimana hukum diwujudkan kedalam bentuk teks, berarti sama saja memindahkan suatu hal yang riil kedalam sebuah teks, sehingga

\footnotetext{
${ }^{30}$ Raz, Joseph, Op Cit, h 221

${ }^{31}$ Huijbers, Theo, 1982, Filsafat Hukum dalam Lintas Sejarah, Karnius, Yogyakarta, h.110

32 Rahadjo, Satjipto, 2009, Hukum dan Prilaku, hidup baik adalah dasar hukum yang baik, Kompas, Jakarta, h.69
} 
apabila hukum tidak dapat mengikuti dinamika masyarakat, karena hukum berbentuk teks bersifat kaku atau hukum itu kaku/keras (Lex dura sed tamen scripta $^{33}$ ), maka tidak dapat terus mewakili dari keadilan dalam kehidupan masyarakat yang terus berkembang. Maka tidak dapat dipungkiri bahwa dalam mencapai substansi keadilan akan berubah menjadi berkeadilan secara teks yang menurut Prof Satjipto Rahadjo kita akan berhadapan dengan substansi pengganti, bukan lagi membicarakan hukum yang sebenarnya, sehingga akan terjadi kecendrungan cara berhukum secara kaku dan regimentation atau cara hidup yang diawasi atau diatur ${ }^{34}$.

Selain itu Prof. Bagir Manan mengatakan bahwa hukum selain sebagai kaedah adalah juga gejala kemasyarakatan, dan kesulitan untuk merumuskan semua bahan hukum tertulis adalah hukum sebagai bagian dari masyarakat mencakup semua aspek kehidupan masyarakat. mengingat aspek masyarakat sangat luas dan kompleks, maka tidak mungkin mewujudkan seluruh aspek kehidupan itu dalam suatu system hukum Perundangundangan atau bentuk hukum tertulis. Hukum Perundang-undangan sebagai hukum tertulis bersifat statis, tidak dapat dengan leluasa mengikuti laju

\footnotetext{
${ }^{33}$ Ibid h.13

${ }^{34}$ Ibid, h. 14
}

pertumbuhan, perkembangan dan perubahan masyarakat yang harus diembannya ${ }^{35}$.

Kekurangan dalam konsep Rule by Law adalah dimana jika diartikan sebagai hukum untuk kepentingan pemerintah, maka hukum dapat digunakan sebagai alat kekuasaan oleh penguasa untuk melakukan tindakan di luar keadilan dan perbuatan tersebut dilegalkan karena perbuatan tersebut diatur oleh Undang-Undang.

Kemudian para hakim kadang membuat keputusan yang tidak mewakili keadilan masyarakat, padahal hakim merupakan tempat menemukan keadilan, dan kadang kala hakim tidak berani untuk berinisiatif untuk membuat suatu yurispudensi, yang disebabkan mereka lebih cendrung memilih jalur aman yaitu keputusan mengikuti Undang-Undang, sehingga ke depannya keputusan mereka tidak mendapatkan masalah atas keputusan yang diambil atau di gugurkan di dalam peradilan yang lebih tinggi, walaupun mereka yakini keputusan yang berdasarkan Undang-Undang tidak mewakili keadilan masyarakat pada saat itu. Hal ini juga disampaikan oleh Jerome Frank yang mengatakan "apabila sikap mengagungkan Undang-Undang telah berlaku di negara yang sepetuhnya diatur oleh Undang-

\footnotetext{
${ }^{35}$ Manan, Bagir dan Magnar, Kuntana, Op.Cit h. $250-251$
} 
Undang, maka proses adaptasi peradilan yang nyata telah disembunyikan di balik kedok ketetapan formal, yang dampak utamannya terciptanya sebuah jurang ${ }^{36}$.

Kemudian hukum tidak dapat mengikuti kebutuhan keadilan dalam masyarakat yang begitu dinamis, karena masyarakat bukan sebua bangunan yang smetris, melainkan memuat banyak kesimpang siuran yang muncul dari sekian banyak interaksi antara para anggota masyarakat ${ }^{37}$. sehingga jika menjalan kan konsep Rule by Law secara murni, maka hasilnya tidak akan sangat memuaskan, karena masalahmasalah yang sebenar-benarnya terjadi di masyarakat tidak terselesaikan secara penuh, yang disebabkan sifat kekakuan dari hukum positif, atau Undang-Undang.

\section{PENUTUP}

\section{Simpulan}

1. Kelebihan dari konsep Rule by Law terletak pada pemberian kepastian , juga dapat menjadi control sosial bagi masyarakat, sehingga menjamin semua warga negarannya dalam tatanan yang baik di semua hubungan timbal balik dalam masyarakat.

2. Kekurangan dari konsep Rule by Law apabila dalam Undang-

\footnotetext{
${ }^{36}$ Frank, Jerome, Op Cit. .h. 263

${ }^{37}$ Rahadjo, Satjipto, Op Cit, h 93
}

Undang yang melegalkan tindakan negara tidak didukung oleh demokrasi dan hak asasi manusia, serta prinsip keadilan, maka akan terjadi pengingkaran terhadap hak asasi manusia, kemiskinan yang luas, dan segregasi rasial, serta jika hukum hanya dimanfaat kan oleh penguasa sebagai alat untuk melegalkan segala bentuk perbuatannya yang melanggar kemanusiaann yang dapat menimbulkan sifat totaliter dari penguasa.

\section{Saran}

1. Bahwa konsep Rule by Law, harus dipertahankan, dan mengambil kelebihan-kelebihan dalam melakukan kontrol sosial kepada masyarakat serta memberikan kepastian kepada masyarakat.

2. Dalam hal menutupi kekurangan Rule by Law, hendaknya setiap Peraturan Perundangan-undangan diberlakukan terdapat asas-asas, nilai-nilai yang ada di masyarakat, sehingga Peraturan Perundangundangan tidak hanya digunakan sebagai sebuah alat oleh penguasa, namun juga dapat mewakili keadilan yang ada di dalam masyarakat 


\section{DAFTAR BACAAN}

\section{Buku :}

Atmaja, I Dewa Gede, 2013, Filsafat Hukum ,Dimensi Tematis \& Historis, Setara Press, Malang.

Frank, Jerome,1963, Law and Modern Mind, Achor Books Donbeday \&Company Inc, New york, USA, diterjemahkan oleh Astuti, Rahmani, 2013,Jerome Frank, Hukum \& Pemikiran Modern, Cet I, Nuansa Candekia, Bandung.

Hadjon, Philiphus M, 2007,Perlindungan Hukum Bagi Rakyat di Indonesia, sebuah studi tentang PrinsipPrinsipnya, Penanganannya oleh Pengadilan dalam Lingkungan Peradilan Umum dan Pembentukan Peradilan Administrasi, Perabadan.

Hayek, Friedrich. 1960. The Constitution of Liberty, University of Chicago Press, Chicago, USA.

Huijbers, Theo, 1982, Filsafat Hukum dalam Lintas Sejarah, Karnius, Yogyakarta

Korkunov, N. M. 1922, General Theory of Law, Second Edition, English Translate By W. G. hastings. The Macmillan Company, New York.

Manan, Bagir dan Magnar, Kuntana, 1997, Beberapa Masalah Hukum tata
Usaha Negara Indonesia, Alumni, Bandung

Muhammad, Abdulkadir, 2004, Hukum dan Penelitian Hukum, PT. Citra Aditya Bakti, Bandung.

Raz, Joseph, 1979, "The Rule of Law and Its Virtue, " in The Authority of Law, Clarendon Press, Oxford.

Rahadjo, Satjipto, 2009, Hukum dan Prilaku, hidup baik adalah dasar hukum yang baik, Kompas, Jakarta.

Sulistiyono ,Adi, 2007, Negara Hukum: Kekuasaan, Konsep, dan Paradigma Moral, Cetakan I, Lembaga Pengembengan Pendidikan (LPP) dan UPT Penerbitan dan percetakan UNS (UNS PRESS) Universitas Sebelas Maret, Surakarta.

Tamanahan, Brian Z, 2004, On The Rule Of Law, History, Politics, Theory, Cambridge University Press, United.Kingdom.

\section{ARTIKEL ELEKTRONIK}

Dicey, A.V., 1952, INTRODUCTION TO THE STUDY OF THE LAW OF THE CONSTITUTION, Mc Millan and Co, Limited St. Martin's Street, London,Part II. Chapters IV-XII, http://www.constitution.org/cmt/avd/1 aw_con.htm, artikel diakses18-012011, pukul 12,30. 
Crisan. Julia,2010, The principles of legality"nullum crimen, nulla poena sine lege" and their role, Effectius Newsletter, Issue 5, France

Sidharta, Arief , 2004, “Kajian Kefilsafatan tentang Negara Hukum”, dalam Jentera (Jurnal Hukum), "Rule of Law", Pusat Studi Hukum dan Kebijakan (PSHK), edisi 3 Tahun II, November, Jakarta. 